Prepared for the U.S. Department of Energy under Contract DE-AC05-76RL01830

\title{
Applicability of the Linear Sorption Isotherm Model to Represent Contaminant Transport Processes in Site-Wide Performance Assessments
}

KJ Cantrell

RJ Serne

GV Last

September 2002

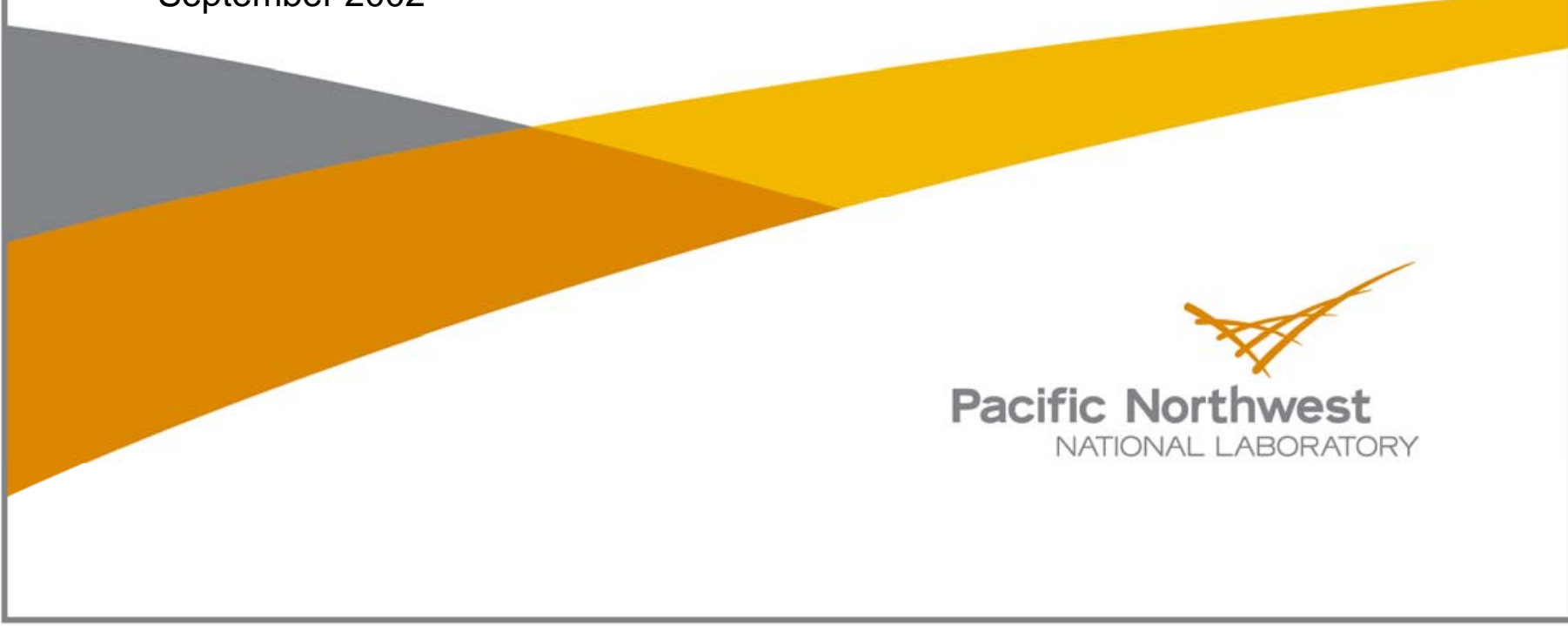




\title{
DISCLAIMER
}

This report was prepared as an account of work sponsored by an agency of the United States Government. Neither the United States Government nor any agency thereof, nor Battelle Memorial Institute, nor any of their employees, makes any warranty, express or implied, or assumes any legal liability or responsibility for the accuracy, completeness, or usefulness of any information, apparatus, product, or process disclosed, or represents that its use would not infringe privately owned rights. Reference herein to any specific commercial product, process, or service by trade name, trademark, manufacturer, or otherwise does not necessarily constitute or imply its endorsement, recommendation, or favoring by the United States Government or any agency thereof, or Battelle Memorial Institute. The views and opinions of authors expressed herein do not necessarily state or reflect those of the United States Government or any agency thereof.

\author{
PACIFIC NORTHWEST NATIONAL LABORATORY \\ operated by \\ BATTELLE \\ for the \\ UNITED STATES DEPARTMENT OF ENERGY \\ under Contract DE-AC05-76RL01830
}

Printed in the United States of America
Available to DOE and DOE contractors from the Office of Scientific and Technical Information,
P.O. Box 62, Oak Ridge, TN 37831-0062;
ph: (865) 576-8401
fax: $(865)$ 576-5728
email: reports@adonis.osti.gov

\begin{abstract}
Available to the public from the National Technical Information Service, U.S. Department of Commerce, 5285 Port Royal Rd., Springfield, VA 22161 ph: (800) 553-6847 fax: $(703) 605-6900$ email: orders@ntis.fedworld.gov online ordering: http://www.ntis.gov/ordering.htm
\end{abstract}

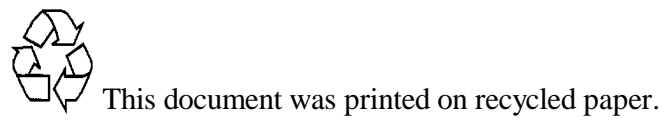




\title{
Applicability of the Linear Sorption Isotherm Model to Represent Contaminant Transport Processes in Site-Wide Performance Assessments $A$ White Paper
}

\author{
K. J. Cantrell \\ R. J. Serne \\ G. V. Last \\ Pacific Northwest National Laboratory \\ Richland, Washington
}

September 18, 2002 


\subsection{Introduction and Technical Need}

The estimation of flux of contaminants through the vadose zone to the groundwater under varying geologic, hydrologic, and chemical conditions is key to making technically credible and sound decisions regarding soil site characterization and remediation, single-shell tank retrieval, and waste site closures (DOE 2000). One of the principal needs identified in the science and technology roadmap (DOE 2000) is the need to improve the conceptual and numerical models that describe the location of contaminants today, and to provide the basis for forecasting future movement of contaminants on both site-specific and site-wide scales.

The State of Knowledge (DOE 1999) and Preliminary Concepts ${ }^{1}$ documents describe the importance of geochemical processes on the transport of contaminants through the Vadose Zone. These processes have been identified in the international list of Features, Events, and Processes (FEPs) (NEA 2000) and included in the list of FEPS currently being developed for Hanford Site asseessments (Soler et al. 2001). The current vision for Hanford site-wide cumulative risk assessments as performed using the System Assessment Capability (SAC) (Kincaid et. al., 2000) is to represent contaminant adsorption using the linear isotherm (empirical distribution coefficient, $\mathrm{K}_{\mathrm{d}}$ ) sorption model.

Integration Project Expert Panel (IPEP) comments indicate that work is required to adequately justify the applicability of the linear sorption model, and to identify and defend the range of $\mathrm{K}_{\mathrm{d}}$ values that are adopted for assessments. The work plans developed for the Science and Technology (S\&T) efforts, SAC, and the Core Projects must answer directly the question of "Is there a scientific basis for the application of the linear sorption isotherm model to the complex wastes of the Hanford Site?" This paper is intended to address these issues.

The reason that well documented justification is required for using the linear sorption $\left(\mathrm{K}_{\mathrm{d}}\right)$ model is that this approach is strictly empirical and is often applicable only under a limited range of physical-chemical conditions. As a result, $\mathrm{K}_{\mathrm{d}}$ values can be applied with confidence only to conditions under which the linear adsorption isotherm has been demonstrated to be applicable. If the sediment/soil mineralogy or physical properties, solution chemistry, or contaminant loading/concentration of the system to be modeled is significantly different from that for which the $K_{d}$ values were determined, significant error could potentially occur in the estimated transport rates. This is because many factors can affect the degree to which a particular contaminant adsorbs to a particular sediment or soil. These factors include: sediment mineralogy and surface area, major ion concentration (complexation and competitive adsorption), $\mathrm{pH}$ of the solution, and concentration of the adsorbate in solution and on the adsorbent. Another important variable that can affect adsorption is kinetics. If the contact time between the contaminant in solution and the sediment is limited by hydrologic factors, equilibrium may not be attained. In this case, modeling with equilibrium $\mathrm{K}_{\mathrm{d}}$ values will overestimate the degree of adsorption. In some cases careful application of currently available geochemical knowledge can often significantly reduce the number of variables that must be considered for evaluating $K_{d}$ values for each particular contaminant (see EPA 1999a, b for identification of key controlling parameters for several radionuclides).

\footnotetext{
${ }^{1}$ Groundwater/Vadose Zone Integration Project, Preliminary System Assessment Capability Concepts for Architecture, Platform and Data Management, September 30, 1999, http://www.bhierc.com/vadose/Workgrps/SAC/Report/9-30rep.pdf
} 


\subsection{Background: Adsorption Mechanisms}

Adsorption, accumulation at the solid-water interface, is one of the primary processes controlling the transport of dissolved contaminants in the vadose zone and groundwater. Adsorption occurs as atoms, molecules, and ions exert forces on each other at this solid-water interface. Adsorption reactions are discussed primarily in terms of intermolecular interactions between solute and solid phases (Stumm and Morgan 1996). These interactions include:

1.) Surface complexation reactions (surface hydrolysis and the formation of coordinative bonds at the surface with metals and with ligands).

2.) Electrostatic interactions at the surfaces, extending over longer distances than chemical forces.

3.) Hydrophobic expulsion of hydrophobic substances (this includes nonpolar organic solutes), which are usually only sparingly soluble in water and tend to reduce their contact with water and seek relatively nonpolar environments, thus accumulating on solid surfaces and becoming adsorbed on organic sorbents.

4.) Adsorption of surfactants (molecules that contain a hydrophobic moiety). Interfacial tension and adsorption are intimately related through the Gibbs adsorption law. Expressed simply this law indicates that substances that reduce surface tension will tend to adsorb at interfaces.

5.) Adsorption of polymers and of polyelectrolytes (humic substances and proteins in particular), is a rather general phenomenon in natural waters and soil systems that has farreaching consequences for the interaction of particles with each other and on the attachments of colloids (and bacteria) to surfaces.

The process in which chemicals become associated with solid phases is often referred to as sorption, especially when one is not sure whether one is dealing with adsorption (onto a twodimensional surface) or $a b$ sorption into a three-dimensional matrix.

The chemical properties of the solution in contact with the solid phase will have a substantial affect on its adsorption characteristics. For example, $\mathrm{pH}$ will have a major influence on the degree of surface hydrolysis, which in turn affects the nature and extent of surface charge. Ionic strength will affect the electrostatic nature of the surface and therefore the electrostatic interactions that can occur. In addition to these affects, the adsorption process itself will change the nature of the surfaces of the solid phase and will influence further adsorption.

The chemical properties of the solution in contact with the solid phase will also affect adsorption as a result of interactions between dissolved species. For example, many metal ions form complexes with major anions in solution. The formation of these complex species can have a major influence on the charge and geometry of the original ion and as a result, significantly alter the sorptive properties of the ion of interest. A special case of complex formation is hydrolysis. Hydrolysis is the formation of complexes with hydroxide ion and is a strong function of $\mathrm{pH}$. Ionic strength can be an important factor that affects the activity of all dissolved ions and as a result the extent of complex formation. Eh can also have a large influent on adsorption by altering the oxidation state of the contaminant and the adsorbent. 


\subsection{Numerical Simulation of Sorption Processes}

Although most of the mechanisms that affect surface sorption described above are fairly well understood, data are not readily available for all the contaminants, sorbents and conditions required for Hanford conditions. Significant problems become apparent when attempting to apply mechanistic modeling approaches to the adsorption of contaminants in some of the complex systems that occur at the Hanford Site. Some of the most significant problems include the large number of contaminants of concern, the large number of potential adsorbents within Hanford sediment, interaction between adsorbent materials that could potentially affect there individual adsorption properties and the wide range of conditions that exist within the various waste sites at Hanford. Mechanistic data simply are not available for all the contaminants, adsorbents and conditions that would be required to model all the potentially important wastes sites at Hanford. In addition the resources required to develop these data would be very large in terms of both cost and time. Additional problems with the application of a mechanistic approach is that a variety of irreversible and rate controlled processes are known to impact adsorption at some sites and many of these kinetic processes are poorly quantified. For example, it is known that desorption $\mathrm{K}_{\mathrm{d}}$ values for many contaminants are known to be significantly higher than their adsorption $\mathrm{K}_{\mathrm{d}}$ values. This indicates that some irreversible adsorption processes may be taking place. Another important process is the irreversible alteration of mineral components of sediments beneath the high-level radioactive waste storage tanks that have been in contact with high $\mathrm{pH}$ tank waste. These alterations are poorly understood and are the subject of ongoing investigations.

Although it is expected that mechanistic investigations of contaminant adsorption will provide invaluable data to improve our understanding of contaminant transport at the Hanford site, this approach alone is not likely to provide all the necessary data required to conduct timely transport modeling for all contaminants and conditions as required for ongoing Hanford site risk assessments.

\subsection{The Linear Sorption Model Approach and its Application at Hanford}

In the linear adsorption model, adsorption is described with a distribution coefficient or $\mathrm{K}_{\mathrm{d}}$ :

$$
\mathrm{K}_{\mathrm{d}}=\mathrm{S} / \mathrm{C}_{\mathrm{aq}}
$$

where $\mathrm{S}$ is the concentration of the contaminant on the solid and $\mathrm{C}_{\mathrm{aq}}$ is the concentration of the contaminant in the aqueous phase. As indicated previously the primary drawback of this approach is that the model is purely empirical and should be applied only to conditions under which the $K_{d}$ was measured. This restriction can be relaxed if a particular variable is known to have no or minimal influence on the adsorption of the contaminant of interest. The advantages of this approach is that it is simple and it can be applied to complex matrices (such as soils and sediments) and solutions for which it would be difficult or impossible to obtain all the required mechanistic surface adsorption data.

An important benefit of the linear adsorption approach at Hanford, is that a relatively extensive database of $\mathrm{K}_{\mathrm{d}}$ values applicable to Hanford sediments is available for the contaminants of most concern over a fairly broad range of conditions (Cantrell et al. 2002). These data have been critically reviewed and cataloged and placed in an accessible database that will be periodically updated as new data become available. This $\mathrm{K}_{\mathrm{d}}$ database (Cantrell et al. 2002) includes available data on the solution chemistry, sediment mineralogy, physical 
properties of the sediment and other experimental parameters used in the determination of the $\mathrm{K}_{\mathrm{d}}$ values.

For most circumstances, the linear adsorption model $\left(\mathrm{K}_{\mathrm{d}}\right.$ model $)$ approach will be adequate for modeling transport through the Hanford system, especially for the far field and low impact sites where geochemical conditions remain fairly constant and contaminant loading of the adsorption sites is low. However, in some situations such as where large changes in chemical conditions occur within a small spatial zone (underneath a leaking high-level waste tank for example), the linear adsorption model may not be appropriate. In these circumstances, rapidly changing chemical conditions can result in large changes in reactivity of the contaminants with surface sites and in large changes in $K_{d}$ values within a small spacial domain. $K_{d}$ values are frequently dependent upon many chemical parameters such as $\mathrm{pH}$, sodium ion concentration, contaminant concentration, etc. High contaminant concentrations can present problems for the linear adsorption model approach. An inherent assumption of the $\mathrm{K}_{\mathrm{d}}$ adsorption model approach is that adsorption is linear. At high surface loadings adsorption typically becomes nonlinear, resulting in error when using the linear adsorption approach. These limitations of the linear adsorption model approach have been dramatically illustrated by the recent work conducted on $\mathrm{Cs}^{+}$adsorption on Hanford sediments under conditions expected underneath a leaking high-level waste tank (Zachara et al., 2002). Under these types of circumstances (e.g., large variation in $\mathrm{pH}$, sodium ion concentration, complexing agents, and contaminant loading) a more sophisticated approach to surface adsorption modeling is warranted.

In addition to the direct influence of chemical variables on $\mathrm{K}_{\mathrm{d}}$ values it should be noted that nearly all $\mathrm{K}_{d}$ value measurements are adsorption $\mathrm{K}_{\mathrm{d}}$ values. In most modeling approaches the $\mathrm{K}_{\mathrm{d}}$ value is assumed to be at equilibrium and reversible. This is not always true. For example, desorption $\mathrm{K}_{d}$ values are frequently higher than adsorption $\mathrm{K}_{\mathrm{d}}$ values. This can result from a number of phenomenon. For example, aging of the sediment after adsorption of a contaminant could potentially result in chemical alterations that could slow the release of adsorbed contaminants or encapsulate the contaminant. Phase changes on or within the sediment or subsequent precipitation of mineral phases onto the surfaces of the sediment are examples of chemical alterations that could lead to these affects. In addition to chemical affects, physical processes can influence adsorption. For example, over time contaminants can diffuse through micropores within sediments to reach adsorption sites that were not initially accessible. This can result in a slow increase in $\mathrm{K}_{d}$ values over time and also result in apparently higher desorption $\mathrm{K}_{d}$ values.

It is envisioned that improvements will be periodically made to site-wide assessment tools (such as SAC) by focusing on the sites, contaminants, and conditions that have a combination of high potential risk and high uncertainty associated with the adsorption data. Through this approach, limited resources can be better allocated to the sites and conditions that are found to have the highest potential risk and the highest potential for risk uncertainty reduction by collecting more accurate adsorption data.

Obtaining more accurate adsorption data may involve determination of $\mathrm{K}_{\mathrm{d}}$ values under conditions that more closely resemble that of the site being modeled or it could involve a more detailed mechanistic study to get a better understanding of the important transport processes and mechanisms involved. The actual approach to be taken will be situation dependent. 


\section{0 $\mathrm{K}_{\mathrm{d}}$ Values as a Function of Waste Stream Designations and Impact Zones}

Currently 6 waste stream descriptions are being used in version 0 of SAC for purposes of assigning $\mathrm{K}_{\mathrm{d}}$ values. Along with the waste stream designation each waste site is broken down into impact zones: high impact, intermediate impact and groundwater (background or insignificant impact). In order to better justify the selection of the $\mathrm{K}_{\mathrm{d}}$ values for each waste stream designation and impact zone, it has been determined that quantitative values (chemical concentrations), for each waste stream category should be assigned. This will provide for a systematic approach for the assignment of $K_{d}$ values that is less ambiguous and more technically defensible. Based on review of the six waste stream designations it was also determined that the six designations should be reduced to three. The current six waste stream designations are:

1. High Organic/Very Acidic

2. High Organic/Near Neutral

3. High Salt/Very Basic

4. Chelates/ High Salt

5. Low Organic/Low Salt/Acidic

6. Low Organic/Low Salt/Near Neutral

These can be simplified to the following three:

1. High Salt

2. Very Acidic

3. Low Salt/Near Neutral

The reasons for these simplifications are as follows. The high organic designation can be eliminated because waste streams that were termed "high organic" generally refer to TBP, hexone, NPH (kerosene), lard oil, carbon tetrachloride. Based on our geochemical experience, tabulations of metal-organic complex stability constants such as Martell (1971), Martell and Smith (1977), Smith and Martell (1982), and the fact that most of these organics are non-polar and relatively hydrophobic molecules, excepting TPB these organics cannot complex metals and radionuclides and will not be important in their transport. Based on these references and our geochemical experience we are confident that TBP is a weak complexant and after any dilution will not be capable of mobilizing metals and radionuclides. Such non polar and/or hydrophobic organic compounds if disposed in large quantities and high concentration could potentially affect radionuclide and metal migration by creating a reducing zone, however, field evidence suggests that this did not occur to any significant extent at the Hanford Site (see Serne and Wood 1990 and references therein). There is also no evidence of such organic compound impacts at other nuclear waste sites across North America (Serne et al. 1990 and 1995).

The acidic waste stream is combined with the near neutral waste stream because waste streams that are not strongly acidic will be neutralized immediately (for all practical purposes). The Chelates/High Salt category is simplified to just High Salt because the effect of high salt is generally greater than that of the chelating agents and chelating agents were released at a relatively small number of sites. Only at very high concentrations of chelates are they capable of significantly mobilizing radionuclides and metals. In addition the chelates themselves can 
adsorb. These arguments are supported by $\mathrm{K}_{\mathrm{d}}$ measurements made in the presence of EDTA and other chelating agents (Cantrell et al. 2002; Serne et al. 2002).

Unfortunately assignment of $\mathrm{K}_{\mathrm{d}}$ values for the very acidic waste is problematic. At Hanford it is believed that the only very acidic waste streams to be disposed were at U-Plant. The waste sites that are believed to have received very acidic waste are trenches $216-\mathrm{U}-1,216-\mathrm{U}-2, \mathrm{U}-8$, U12 and possibly 216-U-17. Due to relatively wide range in $\mathrm{pH}$ values of the acidic wastes that were disposed and a lack of information on the relative amounts of wastes for a particular $\mathrm{pH}$ value it is almost impossible to estimate an appropriate $K_{d}$ value for this waste category. At the current time it is suggested that $\mathrm{K}_{\mathrm{d}}$ values appropriate for low salt/near neutral be used for very acidic sites until better characterization data for the waste stream or acidic impacted waste sites become available.

\subsection{Conclusions and Recommendations}

The linear adsorption model or $\mathrm{K}_{\mathrm{d}}$ approach is a useful and practical approach for modeling contaminant adsorption in transport performance assessments. This empirical approach has the advantages of being simple and the availability of a considerable database of Hanford specific $\mathrm{K}_{\mathrm{d}}$ values measured under a variety of conditions.

An inherent drawback of this approach is its empirical nature. Because the variation in a $\mathrm{K}_{\mathrm{d}}$ value cannot be confidently estimated beyond the range of chemical conditions under which it was measured, the utility of any $\mathrm{K}_{\mathrm{d}}$ measurement is good only for that specific set of conditions. This limitation is not a significant problem as long as the site-specific conditions being modeled do not deviate significantly from that for which $\mathrm{K}_{\mathrm{d}}$ measurements are available. However, for situations in which the concentrations of chemical parameters change rapidly within a small spatial zone (e.g., under a leaking high level waste tank), $\mathrm{K}_{\mathrm{d}}$ values are not generally available for all the important contaminants as a function of all the important parameters in sufficient detail to provide transport modeling results that are sufficiently accurate.

In this situation several approaches could be taken. Each of the possible approaches will require a more detailed knowledge of the geochemical parameters and mechanisms that control adsorption of a particular contaminant under site-specific conditions. The more scientifically rigorous approach would be to conduct detailed mechanistic adsorption studies to determine the influence of all the important geochemical parameters over a broad range of concentrations that could potentially influence adsorption for each contaminant of interest. This approach is likely to be costly and time consuming.

A faster and more economical alternative to the more scientifically rigorous approach is to apply available mechanistic information to design an adsorption study in which $\mathrm{K}_{\mathrm{d}}$ values are determined over a range of geochemical parameters that have the greatest influence on adsorption. These studies would be limited to contaminants that pose the greatest potential risk. It is likely that this approach would only be required for the limited number of waste sites where high concentration wastes were discharged or at leaking high level waste tank sites. Although this approach is not as ideal as a completely mechanistic approach, it would provide a method to obtain more reliable modeling results in a more economical and timely fashion. 
As a means of increasing the scientific defensibility of using the $\mathrm{K}_{\mathrm{d}}$ approach for estimating adsorption in performance assessment modeling it is recommended that a detailed comparison be made with a transport model in which a more rigorous mechanistic approach to adsorption is used. For example, a comprehensive mechanistic Sr adsorption/desorption study for Hanford sedimentary materials is currently being conducted at PNNL (Zachara et al. 2002 Draft Document). This data could be used as the basis for a modeling approach comparison. In this comparison, a site that has previously been well characterized would be selected to aid in the comparison. The modeling approach used in a typical SAC transport scenario would be run and these results would be compared with a modeling run for the same site which utilized the available mechanistic data to the greatest extent practical. This type of comparison would be very useful for establishing the magnitude of error that could be expected when using the more simplistic but more broadly applicable $\mathrm{K}_{\mathrm{d}}$ approach for adsorption modeling in a transport code. Further comparisons with other example contaminants of concern such as uranium could be conducted as data became available.

\subsection{References}

Cantrell, K. J., R. J. Serne, and G. V. Last. 2002. Hanford Contaminant Distribution Cofficient Database and Users Guide. PNNL-13895, Pacific Northwest National Laboratory, Richland, Washington.

DOE (U.S. Department of Energy). 2000. Groundwater/Vadose Zone Integration Project Science and Technology Summary Description. DOE-RL-98-48 Vol. III, Rev. 1. U.S. Department of Energy, Richland, Washington.

DOE (U.S. Department of Energy). 1999. Groundwater/Vadose Zone Integration Project Background Information and State of Knowledge. DOE/RL-98-48. U.S. Department of Energy, Richland, Washington.

EPA. 1999a. Understanding Variation in Partition Coefficient, Kd, Values: Volume I. The Kd Model, Methods of Measurement, and Application of Chemical Reaction Codes. EPA 402R-99-004A, U.S. Environmental Protection Agency, Washington, D.C. prepared by K. M. Krupka, D. I. Kaplan, G. Whelan, R. J. Serne and S. V. Mattigod at the Pacific Northwest National Laboratory, Richland, Washington.

EPA. 1999b. Understanding Variation in Partition Coefficient, Kd, Values: Volume II. Review of Geochemistry and Available Kd Values for Cadmium, Cesium, Chromium, Lead, Plutonium, Radon, Strontium, Thorium, Tritium (3H), and Uranium. EPA 402-R-99004B, U.S. Environmental Protection Agency, Washington, D.C. prepared by K. M. Krupka, D. I. Kaplan, S. V. Mattigod, and R. J. Serne at the Pacific Northwest National Laboratory, Richland, Washington.

Kincaid, C. T., P. W. Eslinger, W. E. Nichols, A. L. Bunn, R. W. Bryce, T. B. Miley, M. C. Richmond, S. F. Snyder, and R. L. Aaberg. 2000. Groundwater/Vadose Zone Integration Project, System Assessment Capability (Revision 0), Assessment Description, Requirements, Software Design, and Test Plan. BHI-01365, Becthel Hanford, Inc., Richland, Washington. 
Martell, A. E. 1971. "Principles of Complex Formation." In Organic Compounds in Aquatic Environments, edited by S. D. Faust and J. V. Hunter. Marcel Dekker, Inc., New York, New York.

Martell, A. E. and R. M. Smith. 1977. Critical Stability Constants Vol. 3: Other Organic Ligands. Plenum Press, New York, New York.

Nuclear Energy Agency (NEA). 2000. Features, Events, and Processes (FEPs) for Geologic Disposal of Radioactive Waste, An International Database. Organisation For Economic Co-operation and Development (OECD) Publications, France.

Serne, R. J. and M. I. Wood. 1990. Hanford Waste-Form Release and Sediment Interaction: A Status Report with Rationale and Recommendations for Additional Studies, PNL-7297, Pacific Northwest Laboratory, Richland, Washington.

Serne, R. J., R. C. Arthur, and K. M. Krupka. 1990. Review of Geochemical Processes and Codes for Assessment of Radionuclide Migration Potential at Commercial LLW Sites. NUREG/CR-5548, U.S. Nuclear Regulatory Commission, Washington, D.C.

Serne, R. J., A. R. Felmy, K. J. Cantrell, K. M. Krupka, J. A. Campbell, H. Bolton, and J.K Fredrickson. 1995. Characterization of Radionuclide-Chelating Agent Complexes Found in LLW Decontamination Waste: Literature Review. NUREG/CR-6124, U.S. Nuclear Regulatory Commission, Washington, D.C.

Smith, R. M. and A. E. Martell. 1982. Critical Stability Constants. Plenum Press, New York, New York.

Soler, L., G. V. Last, B. A. Napier, V. J. Rohay, and F. J. Schelling. 2001. The Application of Feature, Event and Process Methodology at the Hanford Site. BHI-01573, Bechtel Hanford, Inc. Richland, Washington.

Stumm, W. and J. J. Morgan. 1996. Aquatic Chemistry, ( $3^{\text {rd }}$ Edition). John Wiley \& Sons, Inc., New York, New York.

Zachara, J. M., S.C. Smith, C. Liu, J. P. McKinley, R. J. Serne, and P. L. Gassman. 2002. Sorption of Cs + to Micaceous Subsurface Sediments from the Hanford Site, USA. Geochim. Cosmochim. Acta, 66, 193-211. 